\title{
Synthesis and characterization of activated carbon from jute fibers for hydrogen storage
}

\author{
Thangavel Ramesh, Natarajan Rajalakshmi*, and Kaveripatnam S. Dhathathreyan \\ Centre for Fuel Cell Technology, International Advanced Research Centre for Powder Metallurgy and New Materials (ARCI), \\ 2nd Floor, IIT-M Research Park, Phase-1, 6, Kanagam Road, Taramani, Chennai 600113, Tamil Nadu, India
}

Received: 24 August 2016 / Received in final form: 31 January 2017 / Accepted: 7 March 2017

\begin{abstract}
Activated carbons (ACs) are being used as energy storage material especially for hydrogen storage application. In the present work, AC materials were synthesized from jute fibers, activated and treated using $\mathrm{KOH}$ to increase the porosity of samples. These AC samples retained the fibrous structure even after chemical activation at high temperature of $700{ }^{\circ} \mathrm{C}$. Channel like structures were formed which helps to increase the hydrogen storage capacity. The surface area of these samples varied from 380 to $1220 \mathrm{~m}^{2} / \mathrm{g}$ due to carbonization and activation treatment. The sample with high surface area of $1224 \mathrm{~m}^{2} / \mathrm{g}$ showed a high hydrogen uptake capacity of 1.2 wt. $\%$ at $30^{\circ} \mathrm{C}$ and 40 bar of $\mathrm{H}_{2}$ gas pressure. This sample also showed a high pore volume of $0.74 \mathrm{~cm}^{3} / \mathrm{g}$. These results indicate that the raw material jute fibers can be used as hydrogen storage medium after thermal and chemical treatment which increases the surface area and micropore volume.
\end{abstract}

\section{Introduction}

Fossil fuels have been used for centuries as an energy source for automobiles and other industrial purposes, without considering the harmful effects caused to the nature and mankind. There also exists a huge gap between the supply of fossil fuels and the demand. The World Energy Outlook (WEO) claims that energy produced mainly from fossil fuel sources, the demand for the fossil fuel continues to grow until 2040 because of the lack of alternatives to road transport, aviation and petrochemicals, according to WEO-2016. These issues have triggered a cause of concern and there is an urgent need to find a replacement for fossil fuels [1-5]. A lot of research is being done to find an alternated renewable resource to fossil fuels. Energy sources such as wind, solar, nuclear, etc., have been studied as an alternative, but the main challenge lies in their efficiency, storage, transportation, etc., for various applications. Hydrogen has been found to be a possible energy carrier due to its high energy per unit mass, which is about three times higher than that generated from gasoline and almost seven times higher than the energy obtained from coal in an equal mass. The combustion of hydrogen also does not release any greenhouse gases [6-8]. There are various methods to store hydrogen in the form of gas, liquid and solid. However, storing of hydrogen in of the set

\footnotetext{
* e-mail: rajalakshmi@arci.res.in
}

medium faces lots of challenges, in terms of its low storage capacity, thermodynamics, cycle life, kinetics, high cost, etc. [9-12]. Porous materials are active materials, generally used for gas separation and purification. Recently these materials find applications in hydrogen storage as the van der Walls interaction between porous materials and adsorbed hydrogen molecules are weak at very low temperature and high pressure.

In recent years, the hydrogen storage on metal organic framework's (MOFs) [3,13-15], zeolite's [16,17] and carbon nanotubes [18-25], graphene [26-28] and activated carbons (ACs) have been reported in the literature by several groups. Among these ACs have proved to be one of the most promising adsorbent material for storage of hydrogen due to their availability, low cost and with tunable surface area. Natural raw materials like corn cob $[29,30]$, rice husks [31,32], nut shells [33], oil seeds [34], coffee bean [35], hemp stem [36], corn stalks [37], etc. have been studied for hydrogen storage. AC can be prepared by physical or chemical activation of raw materials. It has been observed that the activation using chemical reagents gives rise to microporous structures of large specific surface area and pore volume. Activation by chemical methods is done by mixing the carbon sample with chemical reagents like $\mathrm{KOH}, \mathrm{NaOH}, \mathrm{H}_{3} \mathrm{PO}_{4}, \mathrm{ZnCl}_{2}$, etc.

It has been observed that alkali treatment using $\mathrm{KOH}$ and $\mathrm{NaOH}$ at elevated temperature around $700{ }^{\circ} \mathrm{C}$, leads to high specific surface area and total pore volume [21,38,39]. Yang et al. [36] reported that the hydrogen uptake of 
3.28 wt.\% was obtained for AC synthesized using hemp stem, showing a Brunauer-Emmett-Teller (BET) surface area of $3241 \mathrm{~m}^{2} / \mathrm{g}$ and total pore volume of $1.98 \mathrm{~cm}^{3} / \mathrm{g}$ at $-196^{\circ} \mathrm{C}$ and 1 bar. Akasaka et al. [35] reported that the hydrogen storage capacity for coffee beans with a specific surface area of $2070 \mathrm{~m}^{2} / \mathrm{g}$ was found to be $0.6 \mathrm{wt} . \%$ at 120 bar and $25^{\circ} \mathrm{C}$ and the hydrogen absorption capacity increases with increase in micropore volume.

In the present study, ACs from raw jute fibers (Corchorus capsularis) were synthesized by activated chemically using $\mathrm{KOH}$ at various concentrations. The samples were then tested for their surface area, pore volume and hydrogen storage and the results are analyzed along with surface area and pore volume and observed a linear relationship between hydrogen storage capacity and surface area.

\section{Experimental}

Raw jute fibers were obtained from local market. The chemical composition of raw jute fibers is given in Table $1[40,41]$. Fibers were washed by using isopropyl alcohol (IPA) at $50^{\circ} \mathrm{C}$ and dried in an oven at $100^{\circ} \mathrm{C}$ for $24 \mathrm{~h}$ and then carbonized at $700^{\circ} \mathrm{C}$ for $1 \mathrm{~h}$. AC materials were prepared from jute fibers by treatment with $\mathrm{KOH}$. The carbon to $\mathrm{KOH}$ weight ratio prepared was 1:1, 1:3 and 1:5, followed by heat treatment at $700^{\circ} \mathrm{C}$ for $1 \mathrm{~h}$ under Argon flow $(100 \mathrm{~mL} / \mathrm{min})$ and was then cooled to room temperature. The carbonized sample was then washed in hot water and dried at $100^{\circ} \mathrm{C}$ for $24 \mathrm{~h}$ and labeled as JUTE700-1:1, JUTE-700-1:3 and JUTE-700-1:5 respectively.

\section{Characterization}

Powder XRD analysis was performed using a RigakuSmartlab powder diffractometer with $\mathrm{Cu} \mathrm{K} \alpha$ radiation $(40 \mathrm{kV}, 30 \mathrm{~mA})$, at a scan rate of $10^{\circ} / \mathrm{min}$. The microstructure of the samples was evaluated by scanning electron microscope (SEM). The pore characteristics, specific surface area, pore size distribution and pore volume were determined by analyzing of the $\mathrm{N}_{2}$ adsorption isotherm profiles of carbon materials at $-196{ }^{\circ} \mathrm{C}$. The isotherm profiles were obtained using Micromeritics ASAP2020. Before the $\mathrm{N}_{2}$ adsorption measurement, absorbed gases were degassed at $250^{\circ} \mathrm{C}$ for $15 \mathrm{~h}$ under vacuum. BET model was used to calculate the specific surface area. The pore size distribution was obtained by the density function theory (DFT) method [42-44]. FTIR spectra of the ACs were obtained in the $500-4000 \mathrm{~cm}^{-1}$ range using a Perkin Elmer Spectrum1 FT-IR instrument by the KBr pellet technique with resolution of $1 \mathrm{~cm}^{-1}$.

\subsection{Hydrogen storage experiments}

Hydrogen absorption was performed for the samples in the pressure ranges $0-40$ bar and $30^{\circ} \mathrm{C}$ using a high-pressure Automated Sievert's apparatus from Advanced Material Corporation, USA. The leak test of the instrument was carried out using high pure hydrogen $(99.999 \%)$ at high
Table 1. Chemical composition of raw jute fibers from $[40,41]$.

\begin{tabular}{ll}
\hline Content & Composition (\%) \\
\hline Cellulose & $58-63$ \\
Hemi-cellulose & $20-22$ \\
Lignin + pectin & $12-15$ \\
Ash content & 0.62 \\
Carbon & 44.10 \\
Oxygen & 45.70 \\
Nitrogen & 0.10 \\
\hline
\end{tabular}

pressure before start of the experiment under both vacuum and at high pressure at $200{ }^{\circ} \mathrm{C}$ for $24 \mathrm{~h}$. Initially all the samples were evacuated to $10^{-3}$ mbar for $6 \mathrm{~h}$ at $150^{\circ} \mathrm{C}$. A hydrogen uptake study, without the sample, was also carried out at 80 bar and at $R T$. The study showed no hydrogen absorption within the limits of the lowest count of the instrument. The sample tube and the connecting tubes were evacuated and left under the vacuum for $8 \mathrm{~h}$. There was no change in the pressure. Finally the tube was filled with hydrogen gas at 60 bar and left for $4 \mathrm{~h}$. After ascertaining zero leakage, the sample tube was filled with known amount of carbon and was evacuated and heated to $200^{\circ} \mathrm{C}$ for $24 \mathrm{~h}$. When no change in the pressure was observed, the hydrogen adsorption study was carried out by measuring the pressure $(P 1)$ after introducing hydrogen to the sample tube, containing known weight of carbon material. The system was left for $24 \mathrm{~h}$ to attain the equilibrium and the pressure was measured (P2). The amount of hydrogen adsorbed by carbon material was calculated from the pressure difference $(P 1-P 2)$ at a constant volume. As the volume of the system and weight of carbon were known, the amount of hydrogen in wt.\% was calculated. After cooling to room temperature hydrogen adsorption measurements were performed at $30^{\circ} \mathrm{C}$ with the pressure range of 0 40 bar. At particular pressure $(P)$, temperature $(T)$ and volume $(V)$ the amount of stored hydrogen is calculated by using modified Benedict-Webb-Rubin equation of state given in equation (1)

$$
\begin{aligned}
P & =\rho R T+\left(B_{0} R T-A_{0}-\frac{C_{0}}{T^{2}}\right) \rho^{2}+(b R T-a) \rho^{3} \\
& +\alpha a \rho^{6}+\frac{c \rho^{3}}{T^{2}}\left(1+\gamma \rho^{2}\right) \exp \left(-\gamma \rho^{2}\right),
\end{aligned}
$$

where $\rho$ is molar density, $\gamma$ is heat capacity ratio, $A_{0}$, $B_{0}, C_{0}, a, b$ were viral coefficients. The pressure composition isotherms were obtained by change in volume of the sample at a particular pressure. Bulk density of material was used for hydrogen adsorption/desorption calculation $[13,34]$. The tap density was measured by taking the sample in a known volume container and tapped around 150 times in a smooth surface, till it attains the said volume [45]. The experiments were repeated many times to check the reproducibility of the samples. 

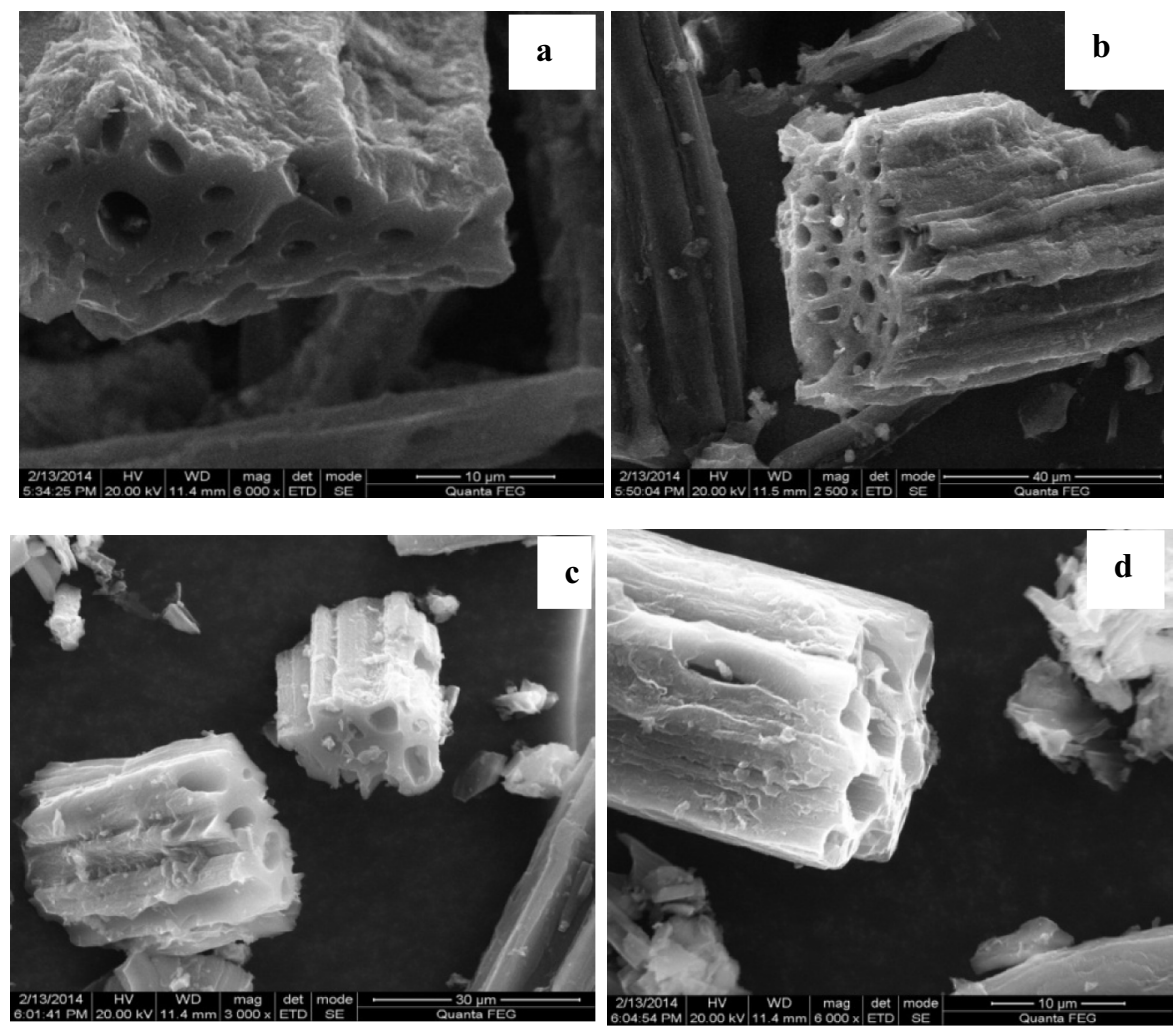

Fig. 1. SEM images of activated carbon from jute fibers. (a) JUTE-700-1 h, (b) JUTE-700-1:1, (c) JUTE-700-1:3 and (d) JUTE-700$1: 3$.

\section{Results and discussion}

The SEM images of the carbon samples prepared by chemical activation of $\mathrm{KOH}$ are shown in Figure 1a-d. The surface morphology shows that the carbonization of jute fibers shows well developed pores on the surface and also showed a fibrous structure after carbonization as shown in Figure 1a. However, further activation using $\mathrm{KOH}$ with different ratio showed channel like structure with bigger pores. However, the fiber length decreases with increase in $\mathrm{KOH}$ activation as can be seen from the SEM images [40].

XRD pattern of carbonized and activated jute fibers is shown in Figure 2, which exhibit two major peaks: (002) planes at $23^{\circ}$ and $(101)$ a less intense peak around $43^{\circ}$. These patterns are known to be characteristic of disordered graphite like structure of amorphous carbon[46]. The graphitic nature of the carbon material is decrease with the increase in chemical agent ratio due to increase in porosity of the material.

Figure 3 shows the adsorption isotherms of the AC materials from jute fibers which exhibit an isotherms of Type I isotherm with H4 hysteresis [35,38,47-49]. This is characteristic of materials of microporous nature due to strong interaction potential between the carbon surface and $\mathrm{N}_{2}$. The $\mathrm{H} 4$ hysteresis observed on activated samples above $p / p_{0}=0.4$ may be due to the narrow slit-like pores. An increase in chemical agent ratio often leads to a larger specific surface area, and thus, contributes to a larger nitrogen adsorption capacity. From Figure 3, one can see the relationship between the specific surface areas, $\mathrm{S}_{\mathrm{BET}}$, calculated using the BET model, and the weight ratio of $\mathrm{KOH} /$ carbon. It has been observed that the specific surface area increases from 382 to $1224 \mathrm{~m}^{2} / \mathrm{g}$ as a function of the $\mathrm{KOH}$ concentration [47]. The textural properties of $\mathrm{AC}$ from jute fibers treated at $700^{\circ} \mathrm{C}$ and at different $\mathrm{KOH}$ ratios are given in Table 2 . It clearly shows that the specific surface area and total pore volume increases with the chemical activating agent increases from 1 to 3 .

The chemical reaction between the chemical agents such as $\mathrm{KOH}$ and the carbon materials may be attributed to the formation of carbonates as shown in the following equations $[48,49]$

$$
6 \mathrm{KOH}+\mathrm{C} \leftrightarrow 2 \mathrm{~K}+3 \mathrm{H}_{2}+2 \mathrm{~K}_{2} \mathrm{CO}_{3} .
$$

Further decomposition of potassium carbonates is also expected at temperatures higher than $700{ }^{\circ} \mathrm{C}$, with respect to the following equations [21],

$$
\begin{gathered}
\mathrm{K}_{2} \mathrm{CO}_{3}+\mathrm{C} \leftrightarrow \mathrm{K}_{2} \mathrm{O}+2 \mathrm{CO}, \\
\mathrm{K}_{2} \mathrm{CO}_{3} \leftrightarrow \mathrm{K}_{2} \mathrm{O}+\mathrm{CO}, \\
2 \mathrm{~K}+\mathrm{CO}_{2} \leftrightarrow \mathrm{K}_{2} \mathrm{O}+\mathrm{CO} .
\end{gathered}
$$

The microporous structure formation in carbon materials may be due to the formation and decomposition of $\mathrm{K}_{2} \mathrm{CO}_{3}$ around $700^{\circ} \mathrm{C}$, thereby enhancing the specific surface area and total pore volume. The BET specific surface area reduces after certain $\mathrm{KOH}$ concentration may 


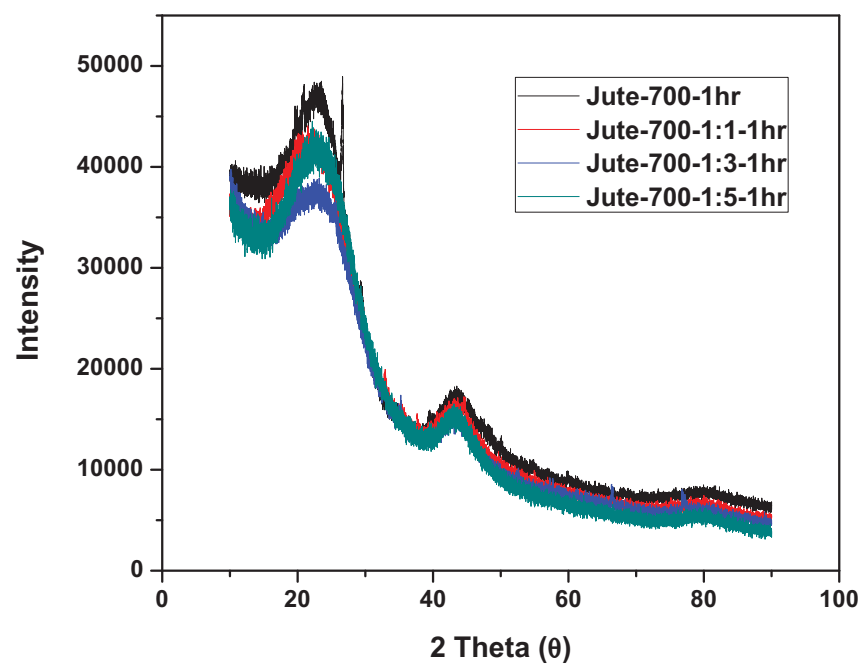

Fig. 2. X-ray diffraction (XRD) pattern of samples.

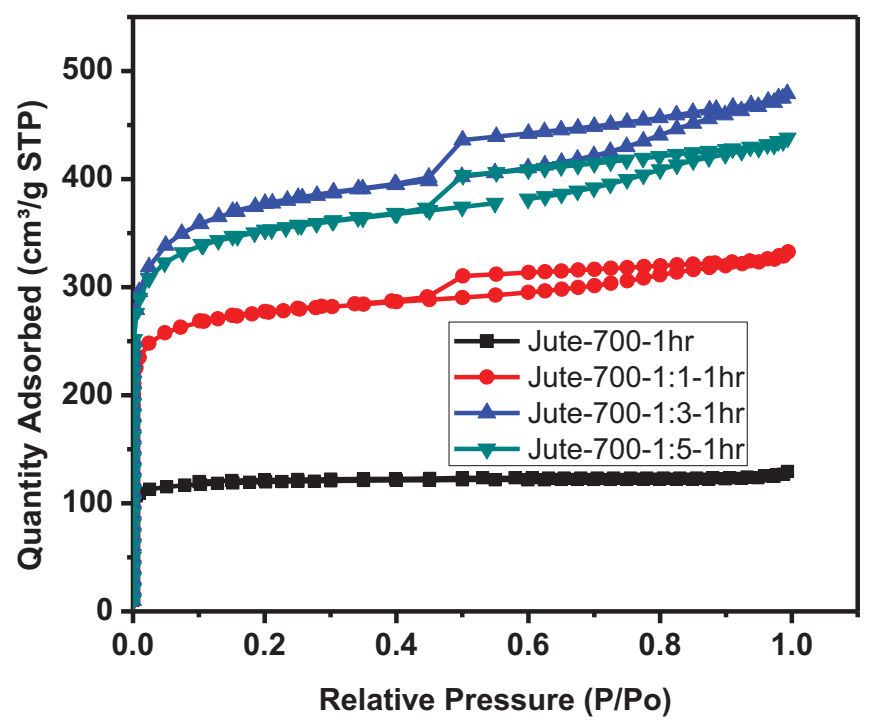

Fig. 3. Nitrogen adsorption isotherms of activated carbon at $-196^{\circ} \mathrm{C}$. Activated carbon weight $=200 \mathrm{mg}$. be due to the effect of pore widening and destruction of pore walls between neighboring pores. The pore size distribution of $\mathrm{AC}$ materials indicated that the diameters of pores range from approximately 0.5 to $1.5 \mathrm{~nm}$ for all the materials, which are shown in Figure 4.

The FT-IR spectrum of all the samples is shown in Figure 5, which provides information on the chemical structure of the materials. It can be observed from the figure that all the samples showed a similar pattern revealing the $\mathrm{O}-\mathrm{H}, \mathrm{C}-\mathrm{H}$ and $\mathrm{C}-\mathrm{C}$ bond stretching. The band at around $3400-3450 \mathrm{~cm}^{-1}$ represents the $\mathrm{O}-\mathrm{H}$ stretching vibration mode of hydroxyl functional groups, while the band at around $2921 \mathrm{~cm}^{-1}$ can be assigned to the $\mathrm{C}-\mathrm{H}$ symmetric and asymmetric vibration mode. The band at around $1630-1640 \mathrm{~cm}^{-1}$ may be due to $\mathrm{C}=\mathrm{C}$ stretching vibration mode of olefinic $\mathrm{C}=\mathrm{C}$ bonds, which is also reported in the literature by Yang et al. [53].

Tap density for all these carbon materials were evaluated and are shown in Table 2 . It has been observed that the density decreases with increase in chemical agent ratio to 3 . It has also been reported that the tap density of the material decreased with increase in specific surface and has been reported by Yang and Lua [33]. They have reported that the ACs from pistachio-nut shells activated by $\mathrm{KOH}$ treatment.

The hydrogen adsorption/desorption studies were investigated on all these jute based carbon materials at various temperatures and pressures, and are shown in Figure 6. It has been observed that all the samples showed a fully reversible hydrogen storage capacity at $303 \mathrm{~K}$. After the activation, a notable increase of the amount of hydrogen uptake is obtained from $0.53 \mathrm{wt} . \%$ for JUTE700 to 0.82 for JUTE-700-1:1, 1.2 for JUTE-700-1:3 and 0.97 wt.\% JUTE-700-1:5.

Figure 7 shows the relationship between hydrogen uptake and the specific surface area. The hydrogen uptake was $0.53-1.2$ wt.\% with surface area ranges from 382 to $1224 \mathrm{~m}^{2} / \mathrm{g}$ at $303 \mathrm{~K}$ and 40 bar. Maximum hydrogen uptake was obtained for higher surface area sample. Figure 8 shows the relationship between amount of hydrogen storage and the micropore surface, when the microporous surface area increased the hydrogen storage also increased. Many literature reports have shown that the surface area has a significant contribution to the hydrogen uptake $[54,55]$.

Figure 9 shows the relationship between the micropore volume and hydrogen uptake. Chemical activation increases the micropore volume from 0.16 to $0.43 \mathrm{~cm}^{3} / \mathrm{g}$

Table 2. Textural properties of jute fiber based activated carbon.

\begin{tabular}{lclllll}
\hline Sample & $\begin{array}{l}\text { Specific } \\
\text { surface area } \\
\left(\mathrm{m}^{2} / \mathrm{g}\right)\end{array}$ & $\begin{array}{l}\text { Micropore } \\
\text { surface area } \\
\left(\mathrm{m}^{2} / \mathrm{g}\right)\end{array}$ & $\begin{array}{l}\text { External } \\
\text { surface area } \\
\left(\mathrm{m}^{2} / \mathrm{g}\right)\end{array}$ & $\begin{array}{l}\text { Total pore } \\
\text { volume } \\
\left(\mathrm{cm}^{3} / \mathrm{g}\right)\end{array}$ & $\begin{array}{l}\text { Micropore } \\
\text { volume } \\
\left(\mathrm{cm}^{3} / \mathrm{g}\right)\end{array}$ & $\begin{array}{l}\text { Tap density } \\
\left(\mathrm{g} / \mathrm{cm}^{3}\right)\end{array}$ \\
\hline JUTE-700-1 h & 382 & 340 & 42 & 0.19 & 0.16 & 0.60 \\
JUTE-700-1 h (1:1) & 894 & 724 & 170 & 0.51 & 0.35 & 0.42 \\
JUTE-700-1 h (1:3) & 1224 & 888 & 336 & 0.74 & 0.43 & 0.30 \\
JUTE-700-1 h (1:5) & 1141 & 873 & 268 & 0.67 & 0.42 & 0.34 \\
\hline
\end{tabular}




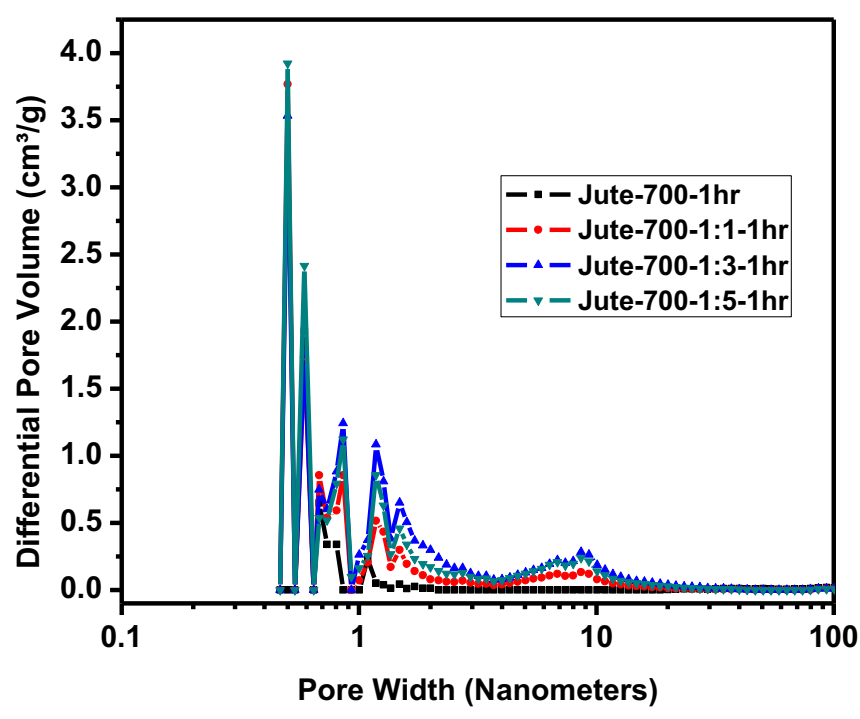

Fig. 4. Pore size distribution of activated carbon calculated using DFT method.

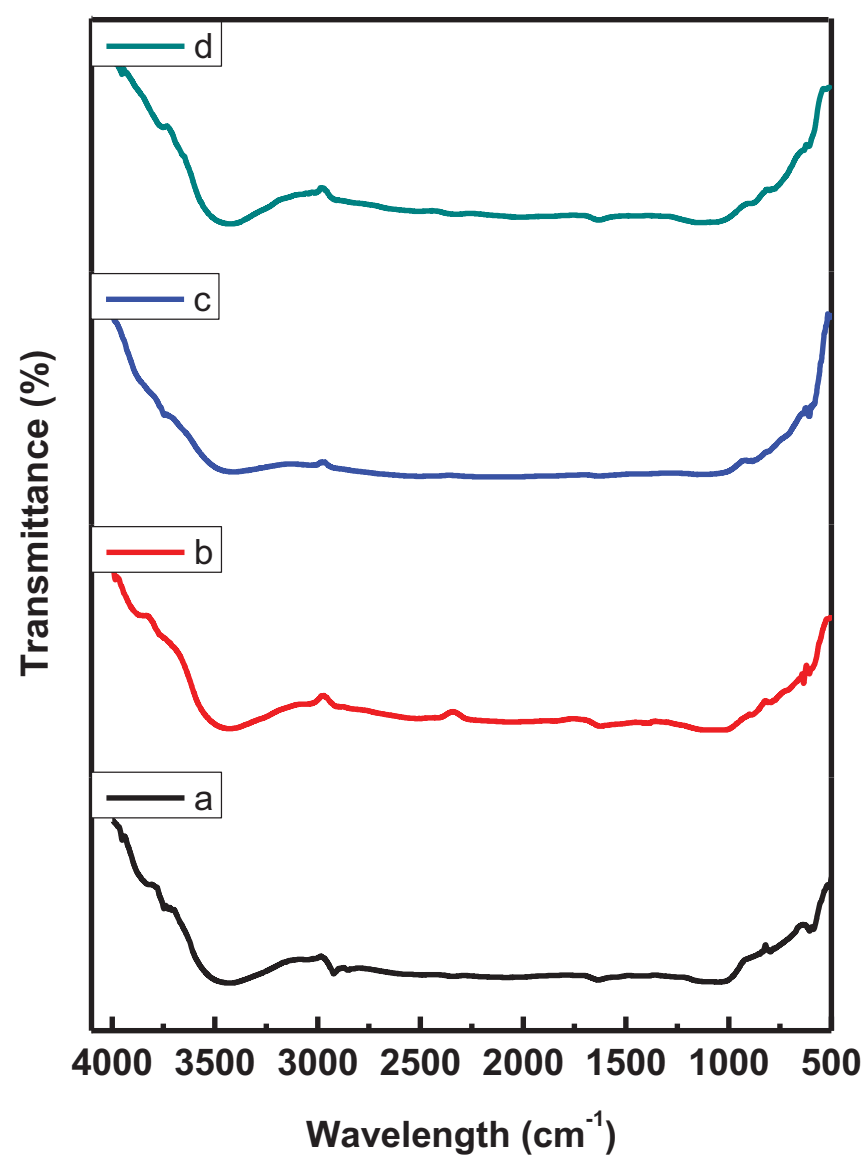

Fig. 5. FTIR spectra of activated carbon from jute fibers. (a) JUTE-700-1 h, (b) JUTE-700-1:1, (c) JUTE-700-1:3 and (d) JUTE-700-1:3.

with increasing weight ratios of $\mathrm{KOH}$. As a result of increased micropore volume, the hydrogen uptake at $303 \mathrm{~K}$ and 40 bar also increases which suggests that the plausible influence of micropore volume on the hydrogen uptake of

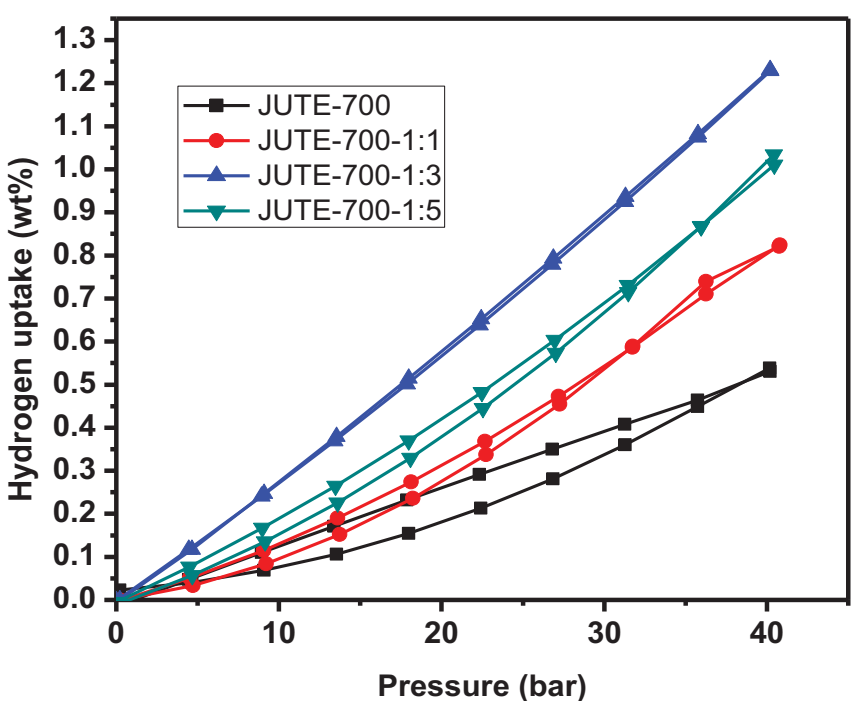

Fig. 6. Hydrogen uptake in activated carbon as a function of equilibrium pressure at $30^{\circ} \mathrm{C}$. Activated carbon weight $=100 \mathrm{mg}$.

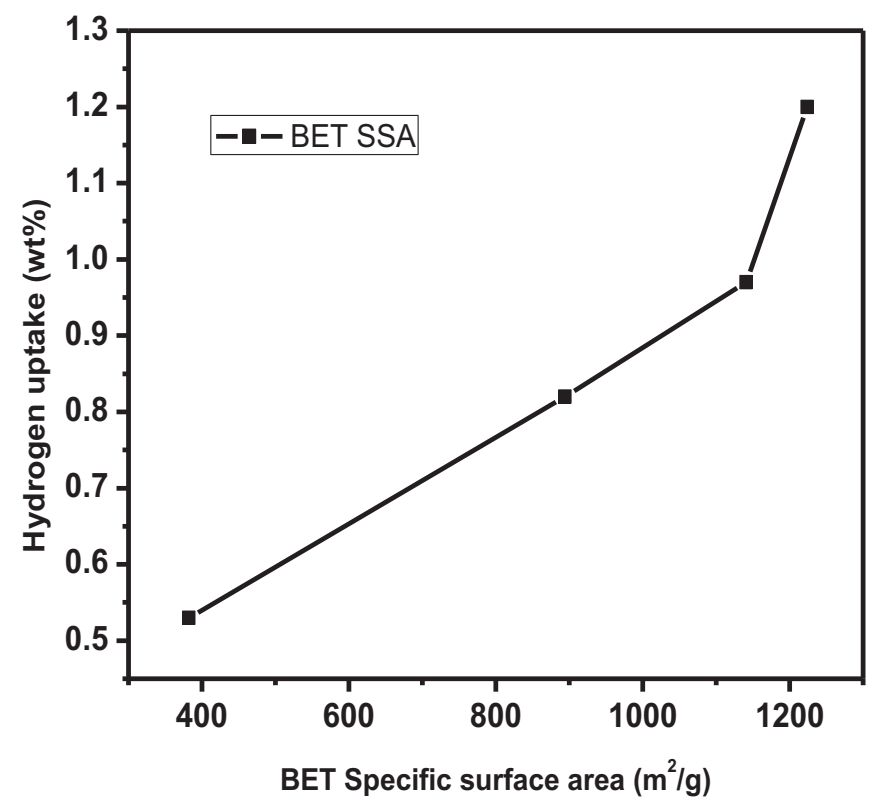

Fig. 7. Relationship between stored maximum $\mathrm{H}_{2}$ content (wt. $\%$ ) and BET specific surface area $\left(\mathrm{m}^{2} / \mathrm{g}\right)$ in activated carbon at $30^{\circ} \mathrm{C}$ and 40 bar.

AC. Akasaka et al. [35] also reported similar result wherein porous carbon materials from coffee bean wastes and suggested that the dimensional change in hydrogen storage configuration occurs from two to three dimension due to increase in micropore volume size. Hence it is very clear that the hydrogen storage depends on both surface area and total pore volume. It was also reported in the literature [34] that low density $\mathrm{AC}$ materials were good adsorbent for hydrogen storage. Increase in porosity on carbon materials leads to lower the tap density and increase the hydrogen uptake $[34,45]$. These results indicate that the 


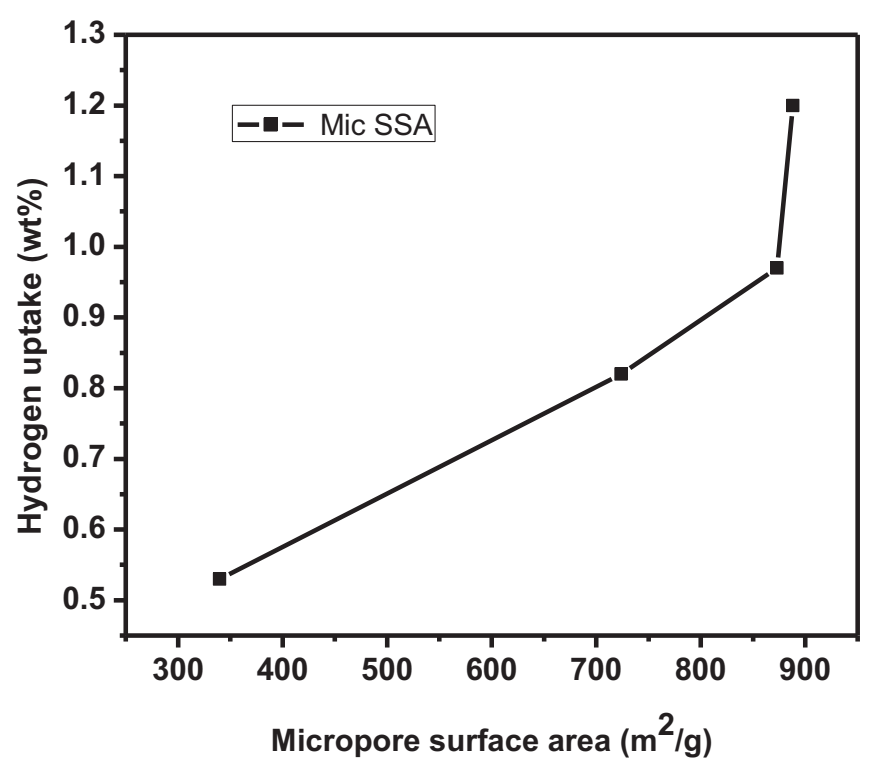

Fig. 8. Relationship between stored maximum $\mathrm{H}_{2}$ content (wt. $\%)$ and micro-pore surface area $\left(\mathrm{m}^{2} / \mathrm{g}\right)$ in activated carbons at $30^{\circ} \mathrm{C}$ and 40 bar.

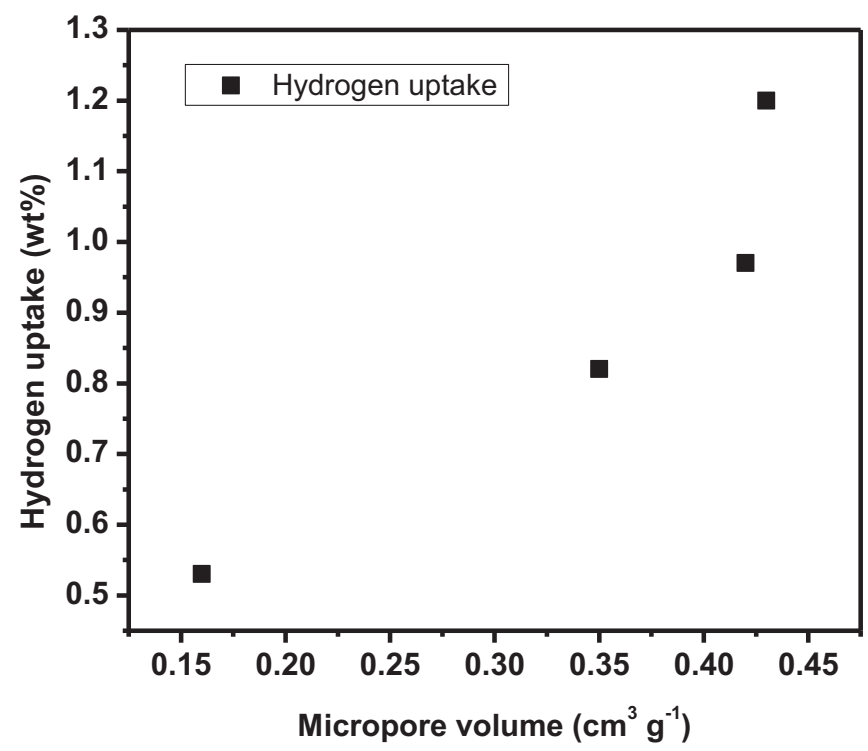

Fig. 9. Relation between stored maximum hydrogen content (wt.\%) and total-pore volume $\left(\mathrm{cm}^{3} / \mathrm{g}\right)$ of activated carbon at $30^{\circ} \mathrm{C}$ and $40 \mathrm{bar}$.

AC materials prepared using jute fibers with high surface area and micropore volume with low tap density are ideal materials for hydrogen storage.

\section{Conclusion}

ACs prepared with different $\mathrm{KOH}$ ratios at $700{ }^{\circ} \mathrm{C}$ were investigated for surface analysis and hydrogen storage studies. The $\mathrm{KOH}$ activation has increased the surface area with enhancement in porosity of the jute fibers and has in turn increased the hydrogen uptake capacities. It was also found that one of the key factor contributing for hydrogen storage is the surface texture of jute fiber. All experimental results have shown significant improvement in the hydrogen uptake capacities for all the samples prepared. Among the samples, JUTE-700-3 showed a higher absorption capacity of $1.2 \mathrm{wt} . \% \mathrm{H}_{2}$ under a pressure of 40 bar at $303 \mathrm{~K}$. The hydrogen uptake capacities of the AC materials have linear relationship with both surface area and micropores. These results indicate that the $\mathrm{AC}$ materials prepared from jute fibers with high surface area and micropore volume with low tap density will be ideal materials for hydrogen storage.

The authors would like to acknowledge Dr. G. Sundararajan, Former Director, ARCI for his constant support and encouragement. The financial support from MNRE, Govt. of India, New Delhi is acknowledged herewith. The authors would like to acknowledge Mr. M. Vivekanandan, project student of SRM University, Chennai for executing some of the experimental work.

\section{References}

1. H. Takagi, H. Hatori, Y. Soneda, N. Yoshizawa, Y. Yamada, Adsorptive hydrogen storage in carbon and porous materials, Mater. Sci. Eng. B 108, 143 (2004)

2. H. Wang, Q. Gao, J. Hu, High hydrogen storage capacity of porous carbons prepared by using activated carbon, J. Am. Chem. Soc. 131, 7016 (2009)

3. J. Li, S. Cheng, Q. Zhao, P. Long, J. Dong, Synthesis and hydrogen-storage behavior of metal-organic framework MOF-5, Int. J. Hydrogen Energy 34, 1377 (2009)

4. S. Park, B. Kim, Y. Lee, M. Cho, Influence of copper electroplating on high pressure hydrogen-storage behaviors of activated carbon fibers, Int. J. Hydrogen Energy 33, 1706 (2008)

5. S.T. Nguyen, H.T. Nguyen, A. Rinaldi, N.P.V. Nguyen, Z. Fan, H.M. Duong, Morphology control and thermal stability of binderless-graphene aerogels from graphite for energy storage applications, Colloids Surf. A Physicochem. Eng. Asp. 414, 352 (2012)

6. W. Zhao, V. Fierro, N. Fernández-Huerta, M.T. Izquierdo, A. Celzard, Hydrogen uptake of high surface area-activated carbons doped with nitrogen, Int. J. Hydrogen Energy 38, 10453 (2013)

7. M. Kunowsky, B. Weinberger, F. Lamaridarkrim, F. Suarezgarcia, D. Cazorlaamoros, A. Linaressolano, Impact of the carbonisation temperature on the activation of carbon fibres and their application for hydrogen storage, Int. J. Hydrogen Energy 33, 3091 (2008)

8. M. Jordá-Beneyto, F. Suárez-García, D. Lozano-Castelló, D. Cazorla-Amorós, A. Linares-Solano, Hydrogen storage on chemically activated carbons and carbon nanomaterials at high pressures, Carbon 45, 293 (2007)

9. L. Zhou, Enhanced storage of hydrogen at the temperature of liquid nitrogen, Int. J. Hydrogen Energy 29, 319 (2004)

10. R. Paggiaro, P. Bénard, W. Polifke, Cryo-adsorptive hydrogen storage on activated carbon. I: thermodynamic analysis of adsorption vessels and comparison with liquid and compressed gas hydrogen storage, Int. J. Hydrogen Energy 35, $638(2010)$ 
11. V. Jiménez, A. Ramírez-Lucas, P. Sánchez, J.L. Valverde, A. Romero, Hydrogen storage in different carbon materials: influence of the porosity development by chemical activation, Appl. Surf. Sci. 258, 2498 (2012)

12. C. Carpetis, W. Peschka, A study on hydrogen storage by use of cryoadsorbents, Int. J. Hydrogen Energy 5, 539 (1980)

13. J.P. Marco-Lozar, J. Juan-Juan, F. Suárez-García, D. Cazorla-Amorós, A. Linares-Solano, MOF-5 and activated carbons as adsorbents for gas storage, Int. J. Hydrogen Energy 37, 2370 (2012)

14. J.J. Purewal, D. Liu, J. Yang, A. Sudik, D.J. Siegel, S. Maurer et al., Increased volumetric hydrogen uptake of MOF-5 by powder densification, Int. J. Hydrogen Energy 37, $2723(2012)$

15. J. Purewal, D. Liu, A. Sudik, M. Veenstra, J. Yang, S. Maurer et al., Improved hydrogen storage and thermal conductivity in high-density MOF-5 composites, J. Phys. Chem. C 116, 20199 (2012)

16. J. Dong, X. Wang, H. Xu, Q. Zhao, J. Li, Hydrogen storage in several microporous zeolites, Int. J. Hydrogen Energy 32, 4998 (2007)

17. M. Fujiwara, Y. Fujio, H. Sakurai, H. Senoh, T. Kiyobayashi, Storage of molecular hydrogen into ZSM-5 zeolite in the ambient atmosphere by the sealing of the micropore outlet, Chem. Eng. Process. Process Intensif. 79, 1 (2014)

18. C.M. Veziri, G. Pilatos, G.N. Karanikolos, A. Labropoulos, K. Kordatos, V. Kasselouri-Rigopoulou et al., Growth and optimization of carbon nanotubes in activated carbon by catalytic chemical vapor deposition, Microporous Mesoporous Mater. 110, 41 (2008)

19. S. Banerjee, K. Dasgupta, A. Kumar, P. Ruz, B. Vishwanadh, J.B. Joshi et al., Comparative evaluation of hydrogen storage behavior of $\mathrm{Pd}$ doped carbon nanotubes prepared by wet impregnation and polyol methods, Int. J. Hydrogen Energy 40, 3268 (2015)

20. C.-H. Chen, C.-C. Huang, Effect of surface characteristics and catalyst loaded amount on hydrogen storage in carbon nanotubes, Microporous Mesoporous Mater. 112, 553 (2008)

21. E. Raymundo-Piñero, P. Azaïs, T. Cacciaguerra, D. CazorlaAmorós, A. Linares-Solano, F. Béguin, $\mathrm{KOH}$ and $\mathrm{NaOH}$ activation mechanisms of multiwalled carbon nanotubes with different structural organisation, Carbon 43, 786 (2005)

22. G. Krishnamurthy, R. Namitha, S. Agarwal, Synthesis of carbon nanotubes and carbon spheres and study of their hydrogen storage property by electrochemical method, Procedia Mater. Sci. 5, 1056 (2014)

23. C.-H. Chen, C.-C. Huang, Enhancement of hydrogen spillover onto carbon nanotubes with defect feature, Microporous Mesoporous Mater. 109, 549 (2008)

24. J. Yuan, Y. Zhu, Y. Li, L. Zhang, L. Li, Effect of multi-wall carbon nanotubes supported palladium addition on hydrogen storage properties of magnesium hydride, Int. J. Hydrogen Energy 39, 10184 (2014)

25. A. Reyhani, S.Z. Mortazavi, S. Mirershadi, A.Z. Moshfegh, P. Parvin, A.N. Golikand, Hydrogen storage in decorated multiwalled carbon nanotubes by $\mathrm{Ca}, \mathrm{Co}, \mathrm{Fe}, \mathrm{Ni}$, and $\mathrm{Pd}$ nanoparticles under ambient conditions, J. Phys. Chem. C 115, 6994 (2011)

26. B.P. Vinayan, K. Sethupathi, S. Ramaprabhu, Facile synthesis of triangular shaped palladium nanoparticles decorated nitrogen doped graphene and their catalytic study for renewable energy applications, Int. J. Hydrogen Energy 38, 2240 (2013)
27. Z.M. Ao, Q. Jiang, R.Q. Zhang, T.T. Tan, S. Li, Al doped graphene: a promising material for hydrogen storage at room temperature, J. Appl. Phys. 105, 1 (2009)

28. Z. Ao, S. Li, Hydrogenation of graphene and hydrogen diffusion behavior on graphene/graphane interface, Graphene Simul., 53 (2011)

29. C. Zhang, Z. Geng, M. Cai, J. Zhang, X. Liu, H. Xin et al., Microstructure regulation of super activated carbon from biomass source corncob with enhanced hydrogen uptake, Int. J. Hydrogen Energy 38, 9243 (2013)

30. N. Rajalakshmi, B.Y. Sarada, K.S. Dhathathreyan, Porous carbon nanomaterial from corncob as hydrogen storage material, Adv. Porous Mater. 5, 28 (2015)

31. Y. Chen, Y. Zhu, Z. Wang, Y. Li, L. Wang, L. Ding et al., Application studies of activated carbon derived from rice husks produced by chemical-thermal process - a review, Adv. Colloid Interface Sci. 163, 39 (2011)

32. H. Chen, H. Wang, Z. Xue, L. Yang, Y. Xiao, M. Zheng et al., High hydrogen storage capacity of rice hull based porous carbon, Int. J. Hydrogen Energy 37, 18888 (2012)

33. T. Yang, A.C. Lua, Characteristics of activated carbons prepared from pistachio-nut shells by potassium hydroxide activation, Microporous Mesoporous Mater. 63, 113 (2003)

34. M. Sharon, T. Soga, R. Afre, D. Sathiyamoorthy, K. Dasgupta, S. Bhardwaj et al., Hydrogen storage by carbon materials synthesized from oil seeds and fibrous plant materials, Int. J. Hydrogen Energy 32, 4238 (2007)

35. H. Akasaka, T. Takahata, I. Toda, H. Ono, S. Ohshio, S. Himeno et al., Hydrogen storage ability of porous carbon material fabricated from coffee bean wastes, Int. J. Hydrogen Energy 36, 580 (2011)

36. R. Yang, G. Liu, M. Li, J. Zhang, X. Hao, Preparation and $\mathrm{N}_{2}, \mathrm{CO}_{2}$ and $\mathrm{H}_{2}$ adsorption of super activated carbon derived from biomass source hemp (Cannabis sativa L.) stem, Microporous Mesoporous Mater. 158, 108 (2012)

37. F. Zhang, H. Ma, J. Chen, G.-D. Li, Y. Zhang, J.-S. Chen, Preparation and gas storage of high surface area microporous carbon derived from biomass source cornstalks, Bioresour. Technol. 99, 4803 (2008)

38. A. Minoda, S. Oshima, H. Iki, E. Akiba, Synthesis of KOHactivated porous carbon materials and study of hydrogen adsorption, J. Alloys Compd. 580, S301 (2013)

39. M. Armandi, B. Bonelli, K. Cho, R. Ryoo, E. Garrone, Study of hydrogen physisorption on nanoporous carbon materials of different origin, Int. J. Hydrogen Energy 36, 7937 (2011)

40. N.H. Phan, S. Rio, C. Faur, L. Le Coq, P. Le Cloirec, T.H. Nguyen, Production of fibrous activated carbons from natural cellulose (jute, coconut) fibers for water treatment applications, Carbon 44, 2569 (2006)

41. A. Bledzki, Composites reinforced with cellulose based fibres, Prog. Polym. Sci. 24, 221 (1999)

42. F. Gao, D.-L. Zhao, Y. Li, X.-G. Li, Preparation and hydrogen storage of activated rayon-based carbon fibers with high specific surface area, J. Phys. Chem. Solids 71, 444 (2010)

43. S.J. Yang, J.H. Cho, G.H. Oh, K.S. Nahm, C.R. Park, Easy synthesis of highly nitrogen-enriched graphitic carbon with a high hydrogen storage capacity at room temperature, Carbon 47, 1585 (2009)

44. C. Solar, A. Blanco, A. Vallone, K. Sapag, Adsorption of methane in porous materials as the basis for the storage of natural gas, Nat. Gas 10, 205 (2010) 
45. M. Jordá-Beneyto, D. Lozano-Castelló, F. Suárez-García, D. Cazorla-Amorós, Á. Linares-Solano, Advanced activated carbon monoliths and activated carbons for hydrogen storage, Microporous Mesoporous Mater. 112, 235 (2008)

46. T.-H. Liou, Development of mesoporous structure and high adsorption capacity of biomass-based activated carbon by phosphoric acid and zinc chloride activation, Chem. Eng. J. 158, 129 (2010)

47. C. Bouchelta, M.S. Medjram, O. Bertrand, J.-P. Bellat, Preparation and characterization of activated carbon from date stones by physical activation with steam, J. Anal. Appl. Pyrol. 82, 70 (2008)

48. K. Babel, D. Janasiak, K. Jurewicz, Electrochemical hydrogen storage in activated carbons with different pore structures derived from certain lignocellulose materials, Carbon 50, 5017 (2012)

49. Y. Xia, G.S. Walker, D.M. Grant, R. Mokaya, Hydrogen storage in high surface area carbons: experimental demonstration of the effects of nitrogen doping, J. Am. Chem. Soc., 131, 16493 (2009)
50. H. Xie, Y. Shen, G. Zhou, S. Chen, Y. Song, J. Ren, Effect of preparation conditions on the hydrogen storage capacity of activated carbon adsorbents with super-high specific surface areas, Mater. Chem. Phys. 141, 203 (2013)

51. M. Lillo-Ródenas, D. Cazorla-Amorós, A. Linares-Solano, Understanding chemical reactions between carbons and $\mathrm{NaOH}$ and $\mathrm{KOH}$, Carbon 41, 267 (2003)

52. M.A. Lillo-Ródenas, J. Juan-Juan, D. Cazorla-Amorós, A. Linares-Solano, About reactions occurring during chemical activation with hydroxides, Carbon 42, 1371 (2004)

53. K. Yang, J. Peng, C. Srinivasakannan, L. Zhang, H. Xia, $\mathrm{X}$. Duan, Preparation of high surface area activated carbon from coconut shells using microwave heating, Bioresour. Technol. 101, 6163 (2010)

54. Z. Zheng, Q. Gao, J. Jiang, High hydrogen uptake capacity of mesoporous nitrogen-doped carbons activated using potassium hydroxide, Carbon 48, 2968 (2010)

55. S.-Y. Lee, S.-J. Park, Effect of temperature on activated carbon nanotubes for hydrogen storage behaviors, Int. J. Hydrogen Energy 35, 6757 (2010)

Cite this article as: Thangavel Ramesh, Natarajan Rajalakshmi, Kaveripatnam S. Dhathathreyan, Synthesis and characterization of activated carbon from jute fibers for hydrogen storage, Renew. Energy Environ. Sustain. 2, 4 (2017) 